\title{
Rock Pressure Manifestation in Development Workings Advanced in a Thick Coal Seam
}

\author{
Konstantin Filimonov ${ }^{1, *}$, Danil Zorkov ${ }^{1}$, Sergey Tsibaev $^{1}$, and Aleksandr Kucherenko ${ }^{2}$ \\ ${ }^{1}$ T.F. Gorbachev Kuzbass State Technical University 28 St. Vesennyaya, Kemerovo, 650000, Russian \\ Federation \\ 2 "V. D. Yalevsky" mine, 652207, Kemerovskaya oblast, Kotino, Russian Federation
}

\begin{abstract}
A research of rock pressure manifestations in the seam workings of seam 52 in "V. D. Yalevsky" mine is presented. It is shown that the inspected development workings advanced in a thick seam have a number of peculiarities determining the urgency of their stability research. It is noted that the researches are carried out in the workings subjected to coal extraction influence, as well as in the workings not subjected to that influence. A brief description of the research method including a visual examination of the mine workings and their support elements, instrumental studies of the border rock massif and the theoretical justification of the parameters of rock pressure are given. The following patterns: rock pressure manifestations mostly in the workings sidewalls, a positive time dynamics of rock pressure manifestations, and the increased intensity of manifestations in the workings roof after coal extracting in the face were recorded. The theoretical justification of rock pressure manifestations and the interpretation of the results of instrumental researches are given.
\end{abstract}

\section{Introduction}

The issues of protection of development seam workings are rather widely represented in the regulatory documents and scientific papers. [1, 2, 3]. Most of the researches and recommendations refer to the mine working protection by pillars while extracting a single pillar at a time or the protection of workings for reuse (mainly by a row of breaker props). The researches of this kind were previously made for the workings with frame supports but recently for those with anchor supports too. The variety of mining conditions in mines does not always allow us to estimate the geomechanical processes outside seam workings by means of generally accepted approaches.

One of the atypical cases peculiar to "V. D. Yalevsky" mine, is the maintenance (поддержание) of roadways in a pillar with worked out space on both sides of it. Such roadways are used as water- and (or) gas-drainage roadways, as well as conveyor roadways for above and below mined pillars. In general, this mine has the following peculiarities of seam working, which determine the urgency of this research:

- pillar protection of seam workings which were twice in the zone of coal mining influence;

\footnotetext{
* Corresponding author: fka.rmpi@kuzstu.ru
} 
- the necessity to maintain the workings which have been in the zone of coal mining influence for a long time (up to 10 years);

- the design of workings and advancing them were carried out without taking into account the need for a long-term maintenance, the need of this kind arose later;

- workings were advanced in a seam up to $5.5 \mathrm{~m}$ thick with a coal band left in the bottom (Fig. 1);

- a large cross-sectional area of the workings (up to $22.2 \mathrm{~m}^{2}$ );

- the workings were along the axis of Sokolovskaya syncline or nearby.
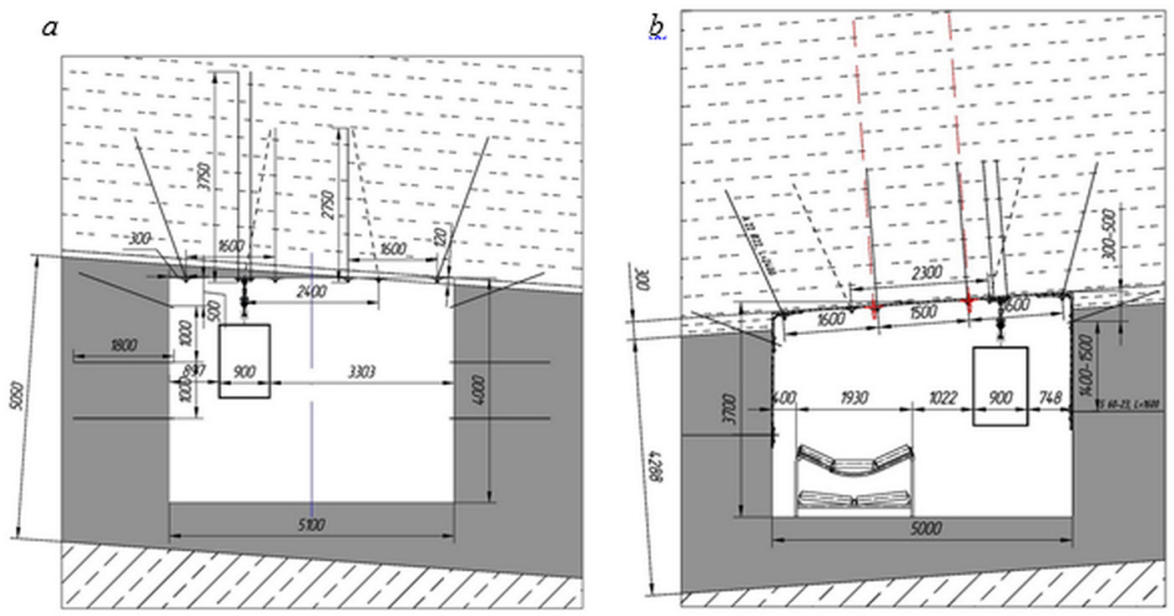

6.

d
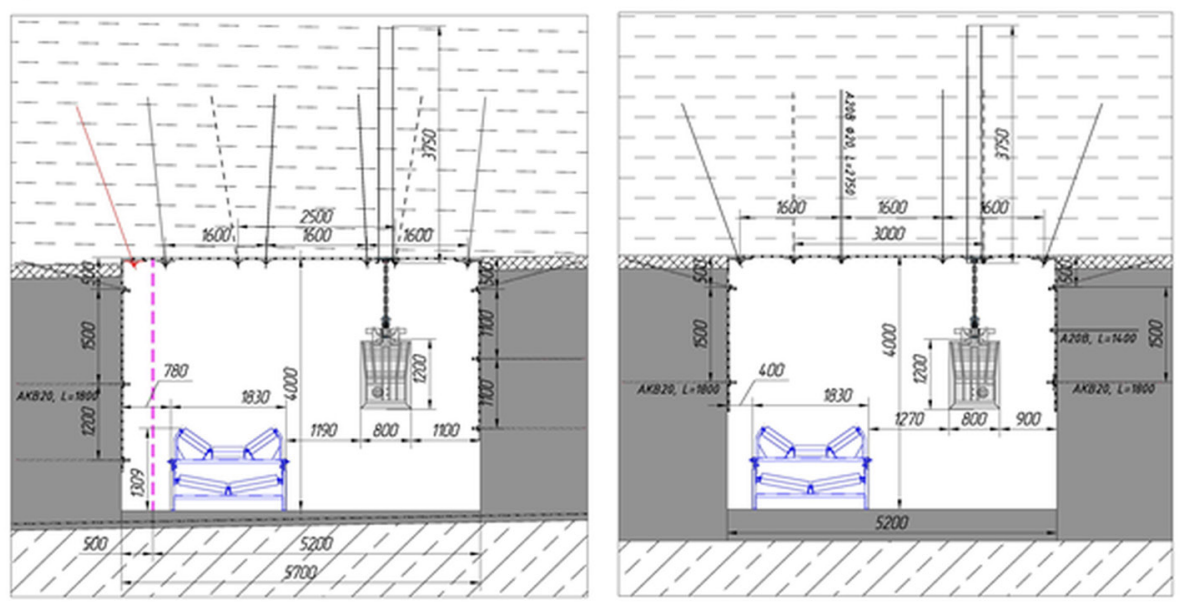

Fig. 1. Designed cross section of drainage roadway (a), of conveyor roadway 5210 (b), of conveyor roadway 5214 (c), of conveyor roadway 5215 and ventilation roadway 5214 (d).

The research began in 2017 [4]. At the first stage of it the state of two roadways which were twice under the influence of advancing was considered. According to the results of this research it was found that advancing affected the state of roadways despite the protection by the pillars. Later new extraction pillars 5214 and 5215 were prepared in the mine. Researches in three workings in these pillars began immediately after driving roadways, before coal advancing affected them. In the future, this will allow obtaining a more complete dynamics of rock pressure manifestations relative to the results for 
roadways investigated since 2017 , and establish the main factors for the development of these manifestations.

Thus, the objects of research are the workings driven in seam 52:

- a drainage roadway and conveyor roadway 5210, supported inside pillars up to $96 \mathrm{~m}$ and up to 72 m wide, respectively;

- conveyor roadway 5214, protected by a pillar $35 \mathrm{~m}$ wide (roadway was formed by expanding the previously driven working);

- ventilation roadway 5214 and conveyor roadway 5215, are located beyond the zone of influence of coalface operations (the distance to the goaf area is $435 \mathrm{~m}$ ).

The parameters of the workings and their supports are shown in Fig. 1. The distance between the transverse rows of anchors in the drainage roadway is $1 \mathrm{~m}$, in the other workings is $0.9 \mathrm{~m}$.

\section{Research method}

The research of the manifestations of rock pressure was carried out by the method including:

- visual inspection of the mine workings and elements of their support;

- instrumental measurements of the border rock massif;

- theoretical basis of rock pressure parameters.

The basis of this method is an in-situ mine monitoring - a visual examination of the mine workings and the elements of their supports before, after and during the mining of adjacent extraction pillars.

The mine workings were examined according to the methodology that takes into account the instruction requirements [5] and included an instrumental assessment of the rock pressure manifestations and deformation of the anchor support elements by measuring the geometry of the mine, the dimensions of rock outfalls, coal spalls from the sidewalls, deformation of mesh support, etc.

When analyzing the state of roadways, areas were identified with geomechanical problems (exfoliation and displacement of rocks to the roadway margin, including support damage) and operational problems (dismantling or damage of supports while drilling degassing wells, arrangement of ventilation facilities, etc.).

Instrumental research of the border rock massif included a georadar and videoendoscope investigation of the roof, an examination of the natural fissuring and strength properties of the coal seam. Georadar investigation allows identifying potentially dangerous sections in roadways having faults in the roof structure, which have not yet manifested themselves in the form of rock displacements in the working. Radarograms are also a source that makes more precise the initial data for the theoretical reasoning of the abutment pressure parameters. Currently, the research method is successfully used in the mines of Kuzbass [6, 7, 8, 9]. A videoendoscope research of the roof allows you to obtain visual data on the structure of the roof rocks and assess the adequacy of the radarogram data. In general, these two methods complement each other. The investigation of the natural fissuring and strength properties of the coal seam was carried out according to classical methods using a mining compass and a BU-39 test probe, respectively.

The theoretical basis of the rock pressure parameters included modeling the stress-strain state of the coal pillars according to the classical laws of geomechanics [10], and the coal and rock massif near the roadways using the finite-element method, which is widely used to solve mining problems $[11,12,13]$. 


\section{Results and discussion}

As a result of a two-year research, the following main forms of manifestation of rock pressure were found that adversely affect keeping mine workings in operational state:

- workings roof and bottom displacement;

- coal spalling from the top of the roadway sidewall spreading to the roof;

- roof caving;

- coal spalling from the middle and lower part of the workings sidewalls including spalling below the installed support;

- layer-by-layer shift of coal in the workings sidewalls.

In most areas with these rock pressure manifestations, damage of anchor support elements was recorded. To add the designed dimensions and support parameters to the mine workings, it is necessary to take away collapsed rock, increase the working height including dinting and strengthen anchor supports with new elements.

Roof and bottom displacements, coal spalling from the top of the sidewall spreading to the roof, are characteristic for roadways twice subjected to the influence of coal mining. Comparison of the designed parameters of the abutment pressure in the pillars and the actual state of the roadways recorded during visual examinations shows correlation between the number of rock pressure manifestations in the roadway sidewalls with the stressed state of the pillars (Fig. 2).

$a$

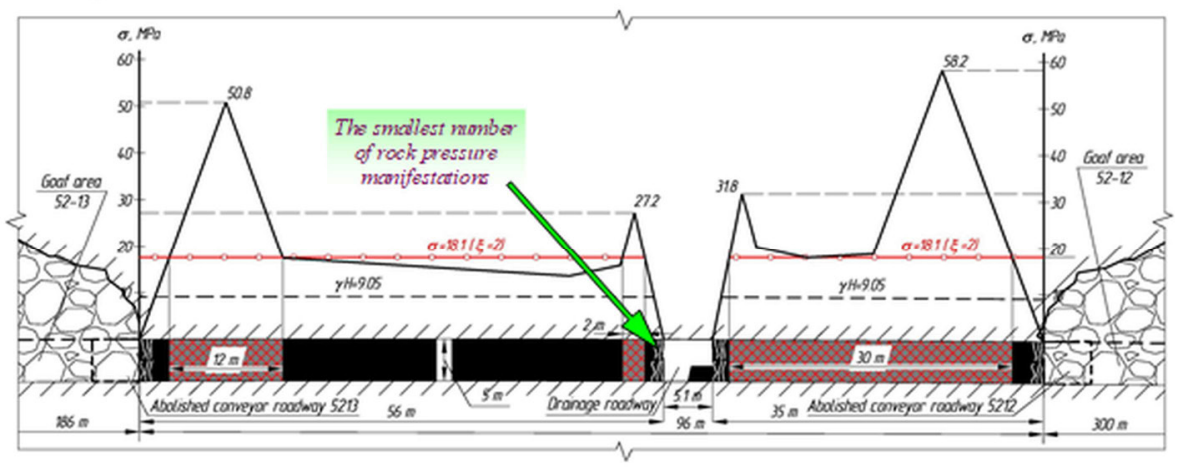

$b$

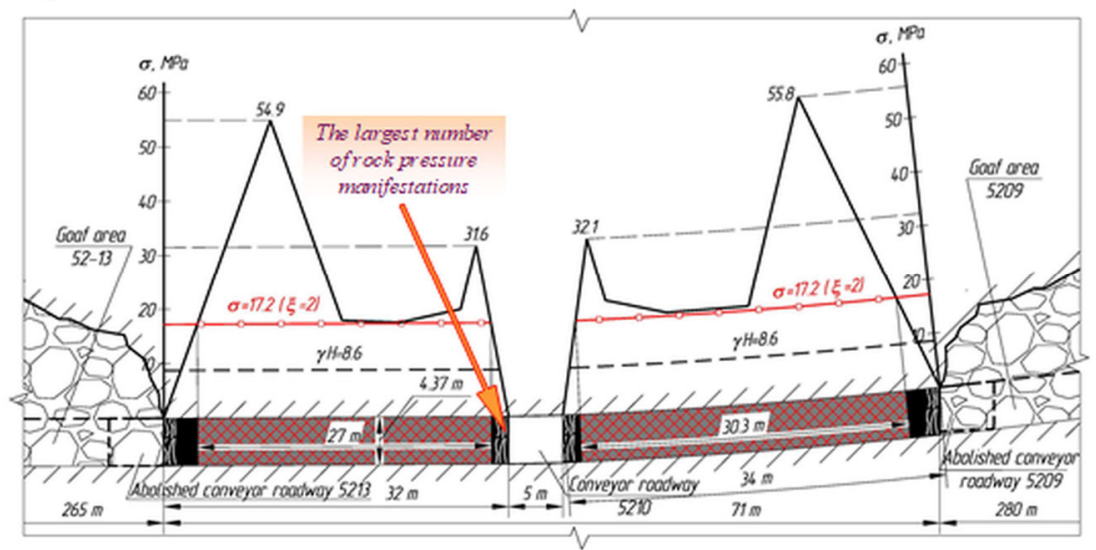

Fig 2. The tension of the pillars protecting the drainage roadway (a) and conveyor roadway 5210 (b). 
The high tension in pillars results in their partial destruction and decrease in bearing capacity which in its turn results in roof and bottom displacement (Fig. 3 b). We consider that it is manifested to a greater extent in the form of displacement of roof layers lying deeper than the anchoring depth. The amount of roof and bottom displacement is supposed to be established at the next stage of research.

The displacement of roof is a negative phenomenon in itself. The height of the roadways significantly decreased along the whole length, and in a number of areas it significantly made mining operations difficult to continue. In addition, the displacement leads to an increase in tension and a decrease in the strength of the coal and rock massif around roadways. Finite-element modeling designated the boundaries of roof and sidewalls as areas with the greatest destruction potential (Fig. 3 a). Figure $3 \mathrm{c}$ demonstrates an example of that abutment pressure manifestation.

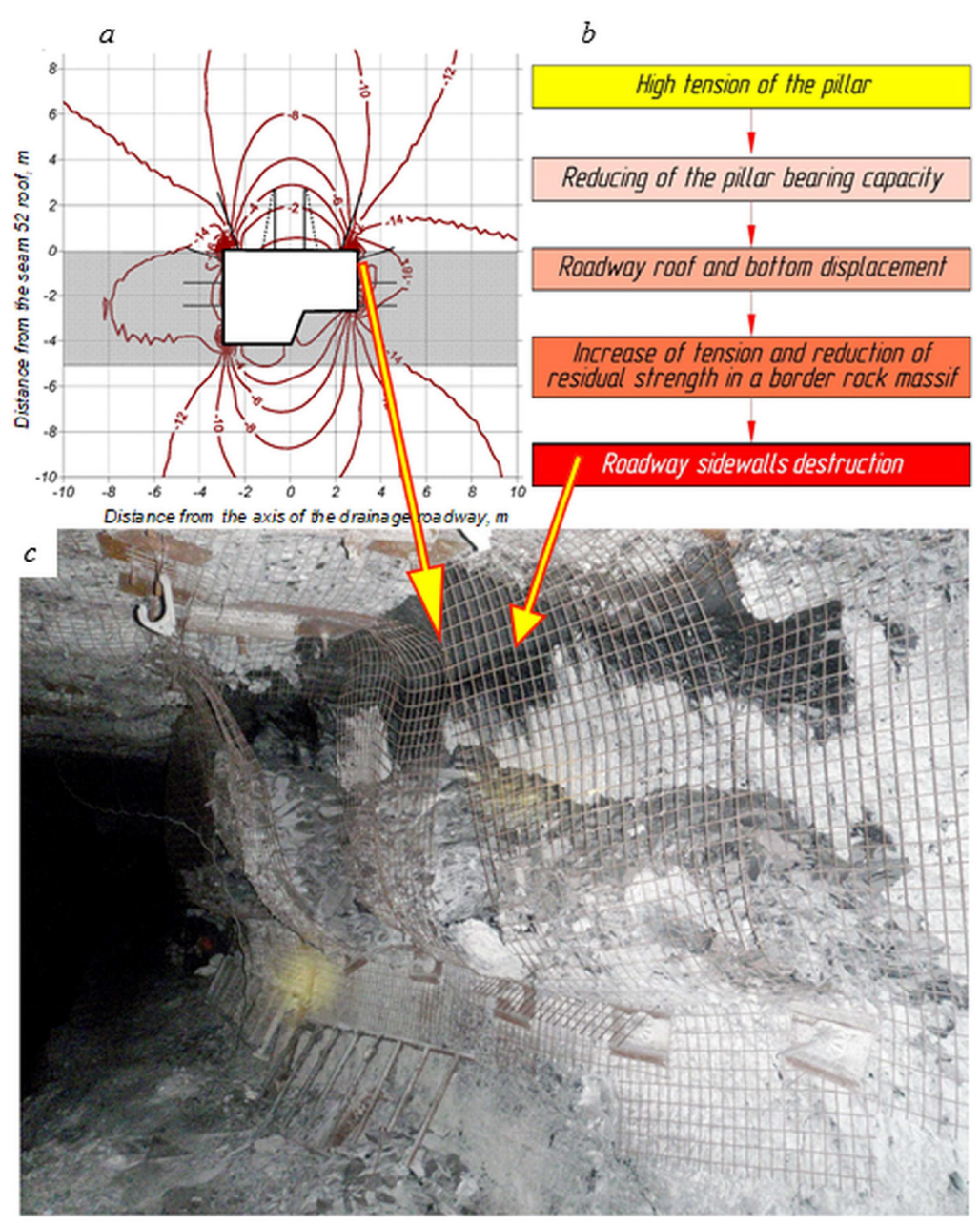

Fig. 3. The theoretical basis of the rock pressure manifestation affecting roof and bottom displacement in the roadway and coal spalling from the top of the roadway sidewall spreading to the roof: $a-$ distribution of vertical tension in a border rock massif; $b$ - abutment pressure manifestation algorithm $\mathrm{c}-$ an example of coal spalling from the top of the roadway sidewall spreading to the roof). 
Despite the fact that the bearing capacity of roof anchors in all five roadways complies with the regulatory requirements, roof caving occurs in some areas. To establish the causes of caving, an investigation of roof structure was made using the georadar and videoendoscope methods (Fig. 4, 5), and the residual strength of that coal and rock massif was modeled by the finite element method (Fig. 6).

$a$

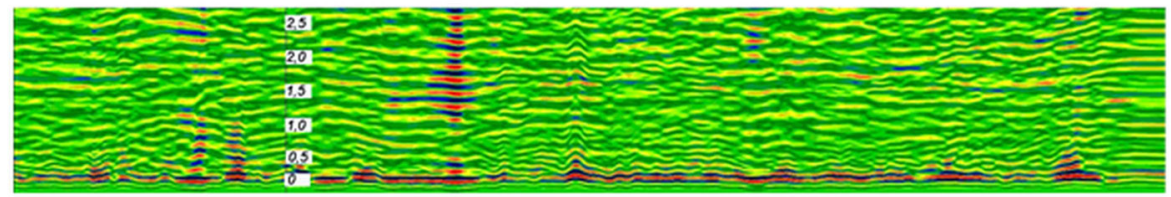

$b$

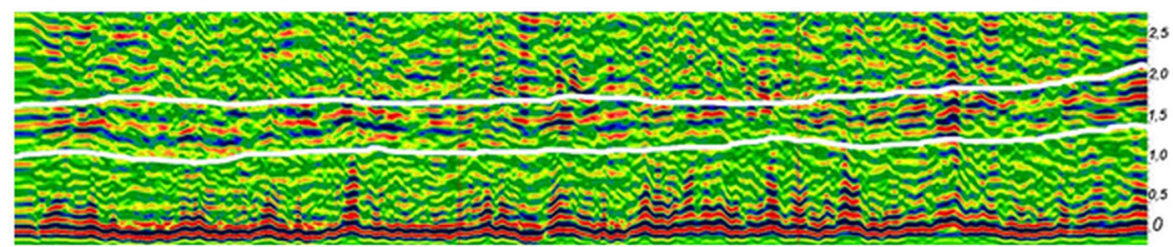

Fig. 4. Roof radarogram: $a$ - the roof is homogeneous; $b$ - rock foliation is at the depth of $1.5 \mathrm{~m}$ (between white curved lines).
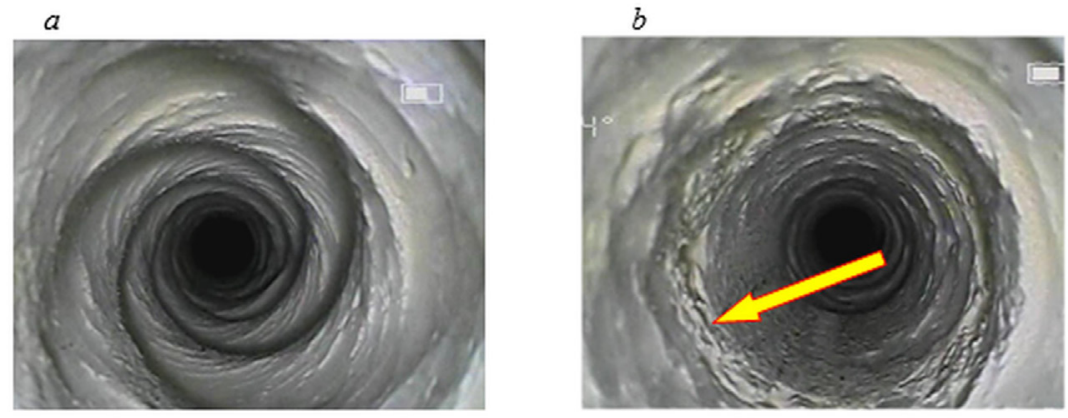

Fig. 5. Videoendoscopic research of the roof: a - homogeneous rock; b - rock foliation and fissuring. 


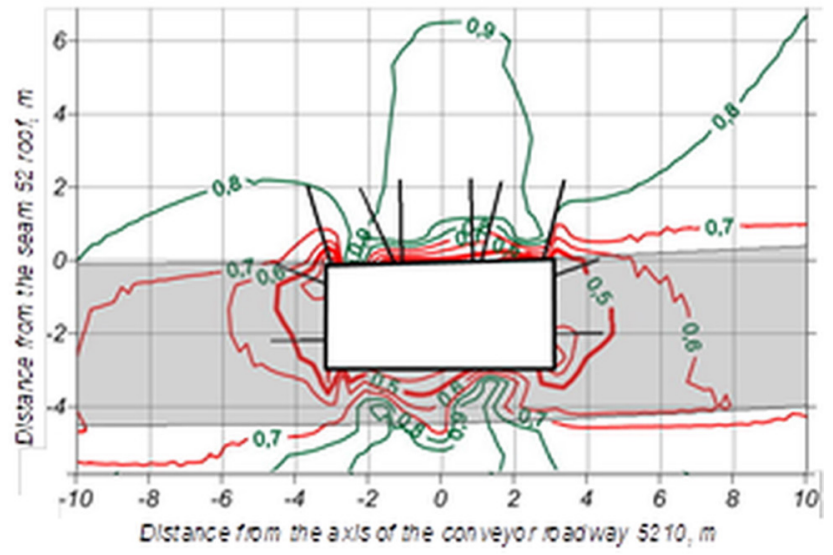

Fig. 6. The ratio of residual rock strength to the initial.

The research showed that in the roadway roof there are sheeted zones (they are between two white curved lines on the radarogram). The anchors fixing area is above these zones, the anchors are firmly fixed. However, the lower layers of anchored rock mass fall down onto the working in some areas (Fig. 7).

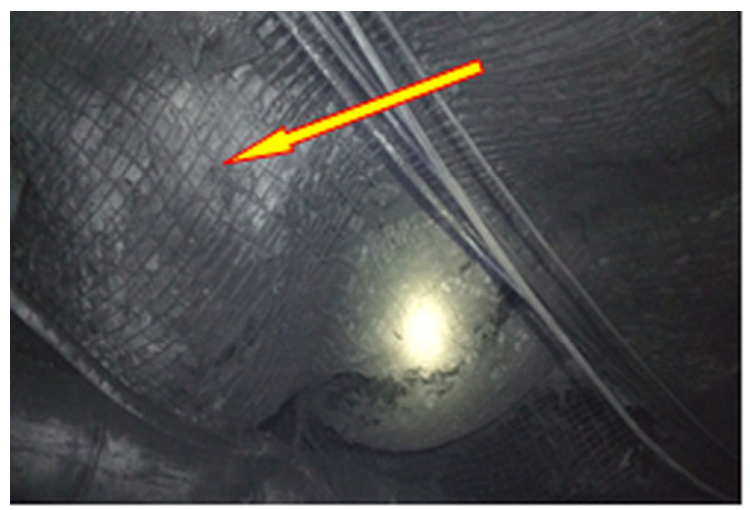

Fig. 7. The example of roof caving (conveyor roadway 5210).

Manifestations of the abutment pressure in the lower sidewall of conveyor roadway 5210 (from the side of extraction pillar 52-13) are quantitatively much greater than the manifestations in other roadways (Fig. 2). There was an assumption that this may be connected not only with the smaller width of the pillar protecting this roadway. A research on natural fissuring and strength properties of the coal seam in this roadway was carried out (Fig. 8). 

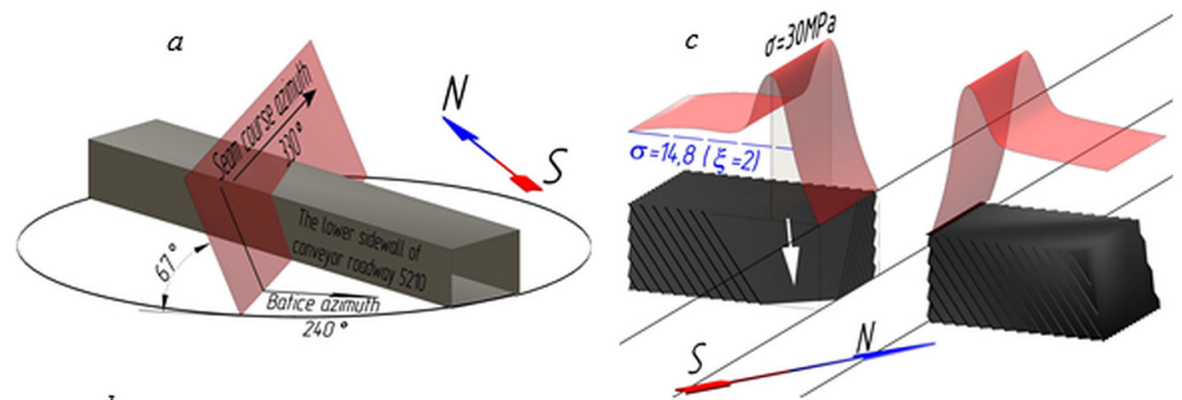

$b$

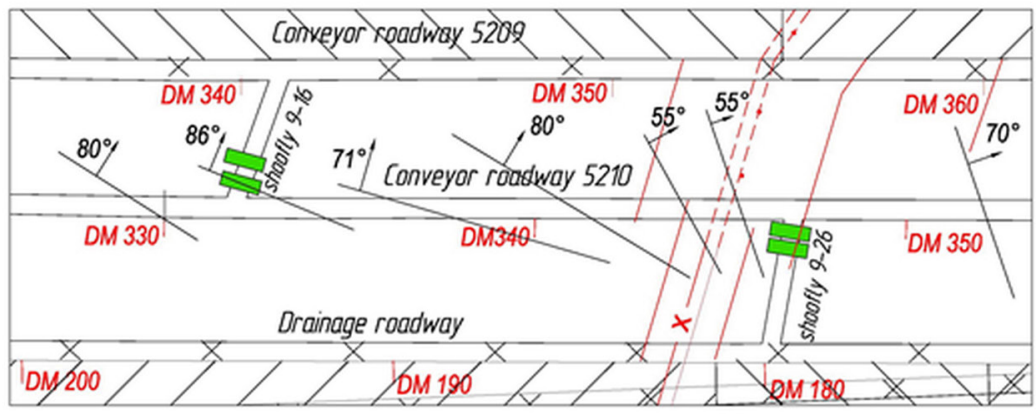

Fig. 8. The research of natural rock fissuring parameters: a $-3 D$ model based on average parameters; $\mathrm{b}-\mathrm{a}$ fragment from the seam 52 mining plan with the results of the research (DM - distance marker); $\mathrm{c}$ - the geomechanical model of the effect of rock foliation on the lower sidewall stability of conveyor roadway 5210 .

It was established that the fissions along the lower side of conveyor roadway 5210 went towards the working, and the ultimate compressive strength of coal was only $7.3 \mathrm{MPa}$, which is lower than the predicted values presented in the mining plan. This value is the minimum for all five roadways. In Fig. $8 \mathrm{a}$ and $\mathrm{b}$ the results of the research are shown, and Fig. $8 \mathrm{c}$ shows a geomechanical model of the effect of fissuring on the lower sidewall stability. Increased tension in the abutment pressure zone of the marginal part of the pillar causes a layer-by-layer shift, and the direction of natural fissuring in the seam results in displacement of disintegrated coal from lower sidewall inside conveyor roadway 5210 .

In workings that are outside of longwall extraction influence (ventilation roadway 5214 and conveyor roadway 5215) and along not resupported sidewall of conveyor roadway 5214, a typical manifestation of rock pressure is coal spalling from the middle and lower parts of the roadways, including a zone below the installed support. The age of workings is one year. With the destruction of the sidewalls, cavities are formed below the support, coal is poured onto the bottom (Fig. 9 a), the anchors stick out half the length; there is no contact of the supporting elements and MP3 with the sidewall (Fig. 9 b). 

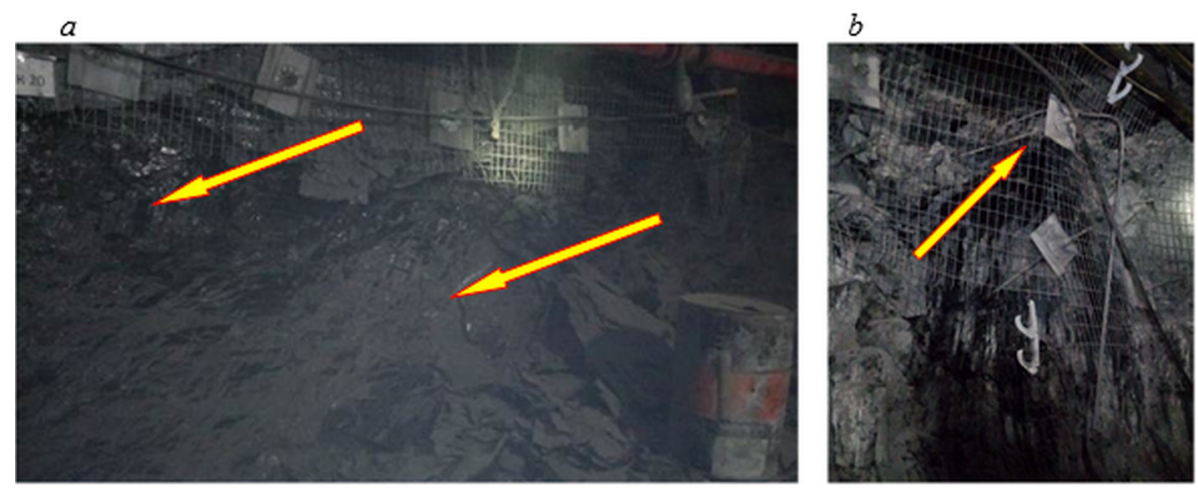

Fig. 9. Examples of destruction of sidewalls: a - cavities are formed; coal falls down to the roadway bottom; $\sigma$ - anchors stick out half the length, there is no contact between supporting elements and mesh and the sidewall.

A georadar research of the roadways sidewalls was carried out. On most radarograms, exfoliation was recorded at the depth of 1 to $3 \mathrm{~m}$ (Fig. 10). Sometimes the exfoliation fissions appear in the roadways.

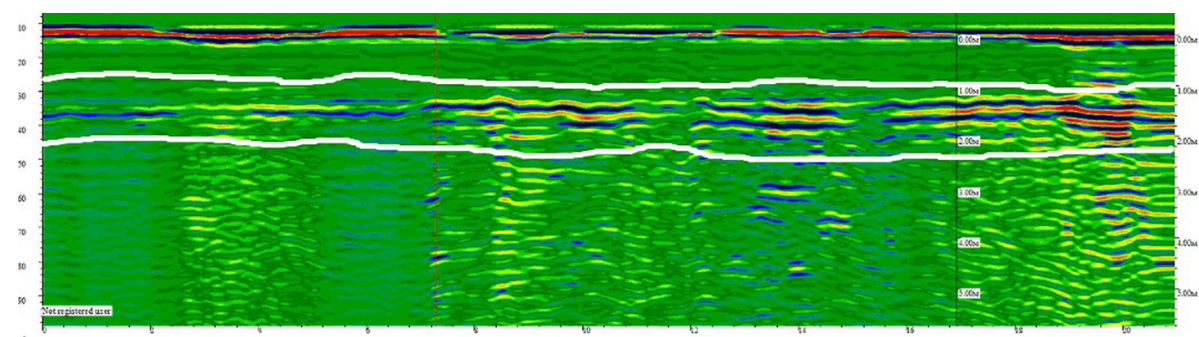

Fig. 10. Radarogram of the conveyor roadway 5215 sidewall: exfoliation at the depth of $1.4 \mathrm{~m}$ (between white curved lines).

The dynamics of rock pressure manifestations in the workings, twice falling into the zone of longwall extraction influence, is shown in Fig. 11 and 12. The general state of the roadways, while taking into account the extent of the areas where damage or absence of support elements without manifestations of rock pressure is recorded, is shown in Fig. 11. The dynamics of manifestations recorded for two years is shown in Fig. 12. Zero on the time axis for the drainage roadway means the completion of pillar extracting 52-13 along the roadway line, and the beginning of mining for conveyor roadway 5210. The analysis of the chart shows the following:

- rock pressure is the most intense in workings sidewalls;

- manifestations of rock pressure have a positive dynamics in time;

- the intensity of rock pressure manifestations in the roof increased after longwall face advancing. 


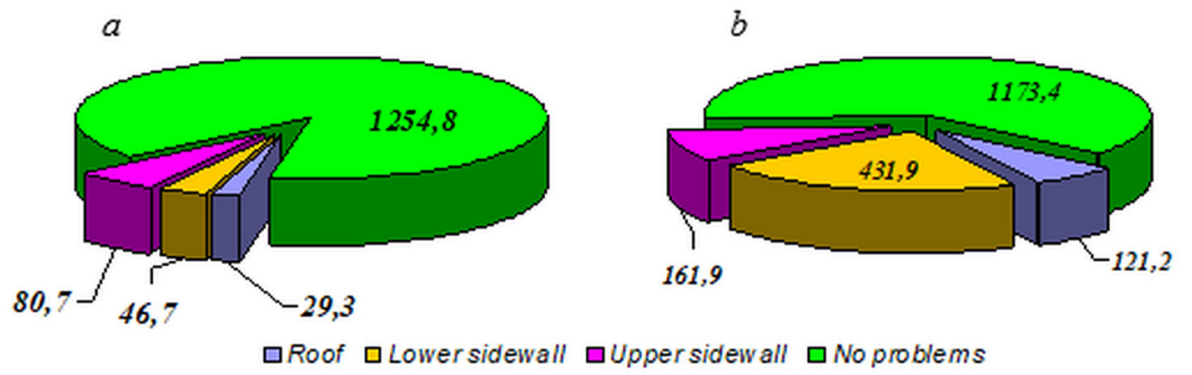

Fig. 11. The total length (in meters) of problem areas of the drainage roadway (a) and conveyor roadway $5210(\mathrm{~b})$.

$a$
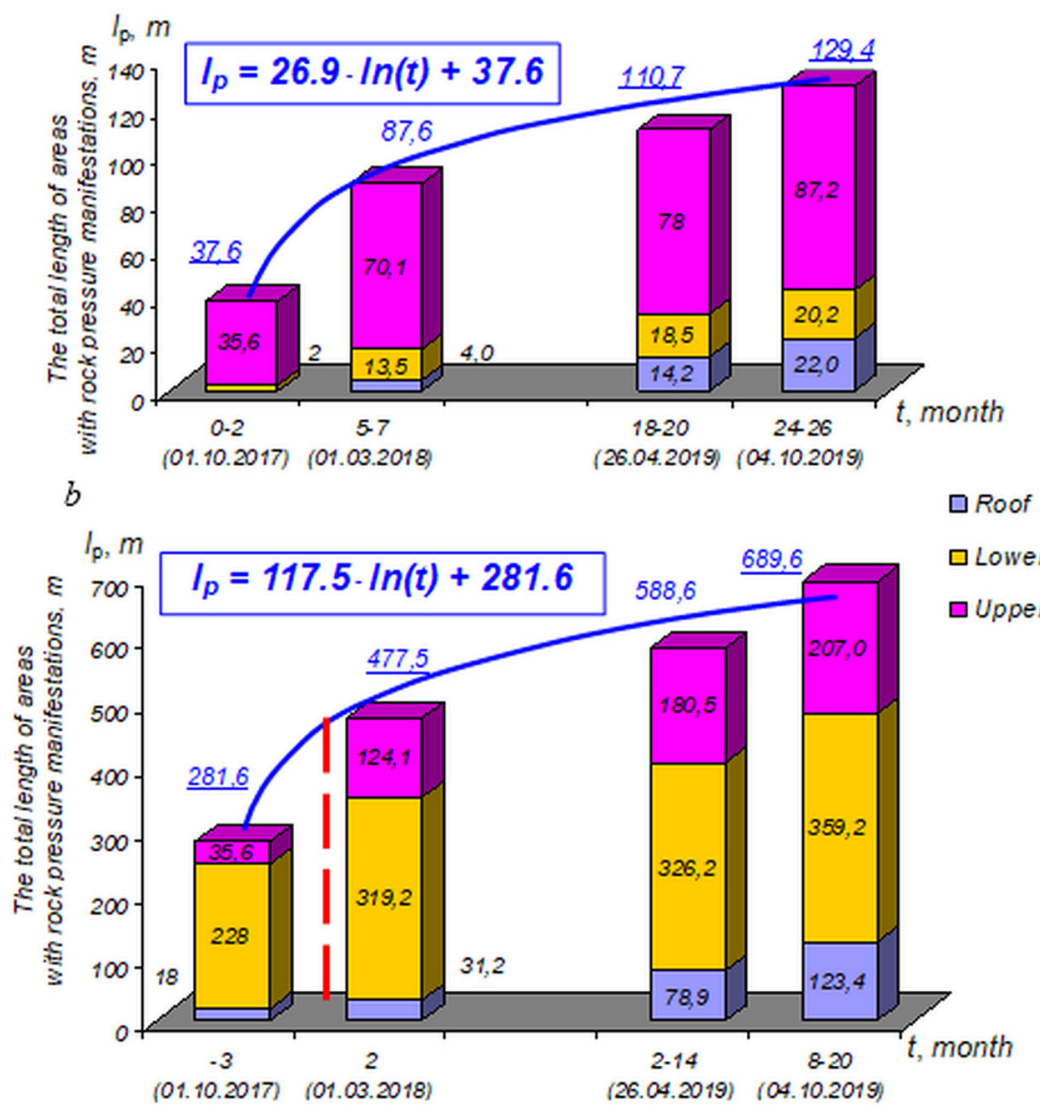

Fig. 12. Dynamics of rock pressure manifestations (in meters) in a drainage roadway (a) and conveyor roadway $5210(\mathrm{~b})$.

A quantitative assessment of the manifestations of rock pressure in the other three workings after the first year of operation is presented in Fig. 13. The most intense manifestation is also recorded in the roadway sidewalls. 

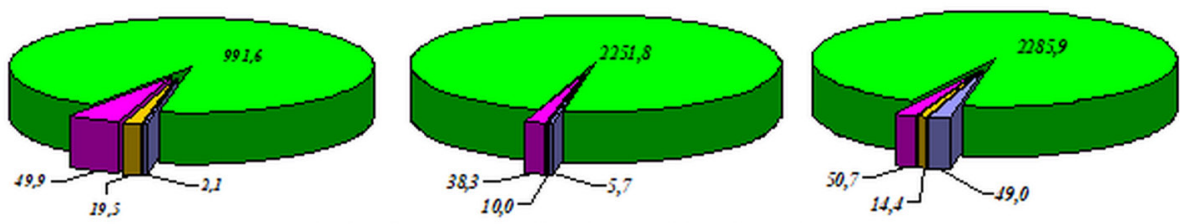

$\square$ Roof $\square$ Lowersidewall $\square$ Uppersidewall $\square$ No problems

Fig. 13. The length (in meters) of areas with rock pressure manifestations in conveyor roadway 5214 (a), ventilation roadway 5214 (b) and conveyor roadway 5215 (c) after the first year of operation.

\section{Conclusion}

In general, according to the results of the research the following conclusions are made:

1. When calculating support parameters for roadways being under the influence of mining for over three years it is necessary to take into account structural and textural factors of a coal seam and enclosing rocks, and also the actual parameters of protection pillars.

2. The parameters of pillars protecting long-term maintained seam workings in a longwall extraction influence area should take into account the rheological factor.

3. The minimum safe installation density of anchor supports (according to the instruction [5]) in workings higher than $3.5 \mathrm{~m}$ does not always ensure lateral stability. It is necessary to investigate the parameters of destruction zones of the coal-rock bearing massif around seam workings with a height above $3.5 \mathrm{~m}$ and cross-sectional area above $18 \mathrm{~m}^{2}$.

\section{References}

1. Guidelines for the rational location, protection and maintenance of workings in coal mines (VNIMI, Leningrad, 1986)

2. G. Ovcharenko, J. of Mining Institute, 205, 54-56 (2013)

3. G. Htumpf, P. Egorov, A. Petrov, B. Krasil'nikov, The rock pressure in development workings in coal mines (Nedra, Moscow, 1996)

4. K. Filimonov, A. Renev, A. Kucherenko, P. Grechishkin, GIAB, 5, 136-148 (2019) DOI: $10.25018 / 0236-1493-2019-05-0-133-148$

5. The instructions for anchoring calculation and application in coal mines (Nedra, Moscow, 2014)

6. A. Kavardakov, E. Kuzin, E. Pudov, GIAB, No. 12, 166-173 (2016)

7. S. Tsibaev, A. Renev, S. Kalinin, D. Zorkov, K. Filimonov, Vestnik of Kuzbass State Technical University, 1, 37-45 (2018) DOI: 10.26730/1999-4125-2018-1-37-45

8. A. Renev, S. Tsibaev, S. Kalinin, Proceedings of the 9th China-Russia Symposium "Coal in the 21st Century: Mining, Intelligent Equipment and Environment Protection", 176, 361-366 (2018) DOI: 10.2991/coal-18.2018.67

9. I. Petukhov, A. Lin'kov, V. Sidorov, Calculation methods in the rock burst and gas emission mechanics (Nedra, Moscow, 1992)

10. V. Fryanov, O. Petrova, T. Petrova, The navigator in the world of science and education, 33, 441-445 (2016)

11. W. Zhu, J. Xu, G. Xu, J. South. Afr. Inst. Min. Metall., 117(11) 1063-1072 (2017) DOI: $10.17159 / 2411-9717 / 2017 /$ v117n11a11

12. E. Karampinos, J. Hadjigeorgiou, M. Pierce, J. South. Afr. Inst. Min. Metall., 118(12), 1243-1250 (2018) DOI: 10.17159/2411-9717/2018/v118n12a2 
13. P. Phanthoudeth, T. Sasaoka, H. Shimada, B. Ulaankhuu, J. Oya, S. Dwiki, T. Karian, GSTF JGS , 3(1), 15-23 (2016) DOI: 10.5176/2335-6774 3.1.26 